\title{
Principal-Agent Analysis and International Delegation: Red Herrings, Theoretical Clarifications, and Empirical Disputes
}

\author{
Mark A. Pollack, \\ Temple University \\ Department of Political Science \\ 461 Gladfelter Hall \\ Philadelphia, PA 19122 \\ E-mail: mark.pollack@temple.edu
}

Paper prepared for presentation at the Workshop on Delegating Sovereignty, Duke University, 3-4 March 2006. 
The principal-agent (PA) approach has become, over the past decade or so, by far the dominant approach to the study of delegation in domestic (American), comparative, and international politics. ${ }^{1}$ Put simply, the PA approach draws from rational-choice theories of domestic and international politics, arguing that instrumentally rational actors (voters or legislators at the domestic level, states at the international level) delegate powers to executive and judicial agents systematically in order to lower the transaction costs of policy-making, and that in doing so they tailor the discretion of their agents, again systematically, as a function of several factors including the demand for credible commitments, the demand for policy-relevant information, and the expected gap between the preferences of the principals and the agents. Following the initial act of delegation, some principal-agent accounts go on to make predictions about the autonomy and influence of executive and judicial agents, which are typically theorized to vary as a function of the administrative and oversight mechanisms available to the principals. As such, the principal-agent approach has been a limited but fruitful middle-range theory, allowing us to problematize and generate multiple, testable hypotheses about delegation and agency in a remarkably wide array of empirical contexts.

Despite these purported benefits, principal-agent approaches have come under sustained criticism in recent years, perhaps most strikingly in my own fields of European Union (EU) studies and international relations, where a number of critics have taken exception to both the theoretical assumptions and the empirical claims of principal-agent analysis. In this memo, I review and engage these critiques, not in order to vanquish PA's foes and vindicate the theory, but rather to parse these critiques out and determine which seem misplaced and which merit further consideration. For this purpose, I review a small group of articles and books, all drawn from IR and EU studies, and all by excellent scholars whose views deserve serious consideration (e.g. McNamara 2002; Kassim and Menon 2003; Johnstone 2003; Barnett and Finnemore 2004; Alter 2006). My focus throughout the memo is on arguments that question the usefulness or empirical adequacy of PA approaches as a whole in the study of IR, rather than on the many works

\footnotetext{
${ }^{1}$ A complete list of citations would be prohibitively long. Key works and reviews in American politics include Epstein and O’Halloran 1999, and Bendor, Glaser and Hammond 2001. Applications to international relations have been most common in the study of the EU (see Franchino 2001, Majone 2001, Pollack 2003, Tallberg 2007), but have increasingly moved into mainstream IR (see e.g. the essays in Hawkins et al. 2006).
} 
that attempt to further elaborate PA analysis in new directions or adapt PA models specifically to IR settings. ${ }^{2}$

At the risk of oversimplification, I group these authors' critiques into three categories. The first, and least interesting, of these categories are the red herrings, the critiques that arise from a misunderstanding or misrepresentation of what PA approaches and their practitioners actually argue. The second and more interesting critique I will consider raises a genuinely interesting theoretical issue - the distinction between agents and trustees, and the applicability of PA analysis to the latter - although as I will demonstrate, this distinction needlessly dichotomizes a continuum of agent discretion and a range of motivations for delegation, and strictly defined is of little relevance to the universe of empirical cases that we wish to explain at this workshop. The third and final group of critiques raises essentially empirical objections to PA analyses, arguing that PA approaches systematically fail to predict correctly either (a) the reasons and the conditions under which political principals delegate powers to agents, or (b) the conditions under which agents enjoy autonomy and influence in domestic and international politics. These last critiques, I argue, have thus far been made in a suggestive rather than a persuasive way, but they have the benefit of articulating increasingly distinctive, clear and (sometimes) testable propositions about delegation and discretion, and of being settled through good empirical work rather than metatheoretical debate.

\section{Red Herrings}

The true red herrings - those critiques of PA analysis that begin from a misunderstanding or mischaracterization of PA analysis - are heard often at conferences and occasionally in early drafts of papers from which they are subsequently, and rightly, expunged, and hence only rarely make it into print in reputable journals and books. Nevertheless, one hears such arguments with sufficient frequency that they are worth noting briefly, if only to rebut them in a sort of theoretical clearing of the brush. I deal for the sake of brevity with four of the most common red herrings, although I note that

\footnotetext{
2 See e.g. Lyne, Nielsen and Tierney 2006, and the rest of the essays in Hawkins et al. 2006.
} 
even some of these red herrings raise important questions that could push analyses of international agents in potentially interesting directions.

The first, and most easily rebutted, of these red herrings is that international organizations like the European Commission or the European Court of Justice (ECJ) are not "mere agents" of their political principals, but rather possess independent preferences and can influence political outcomes in their own right. Criticisms like these simply misunderstand the definition of "agent" in principal-agent analysis, in which agents are indeed assumed to have independent preferences. Far from presupposing that agents slavishly follow the preferences of their principals, PA analyses give us a theoretical language for problematizing and generating testable hypotheses about the sources and the extent of agents' autonomy and influence.

A second and related red herring arises from the assumption that principal-agent analyses as such are characterized by some bias in its answer to the question, "Do Agents Matter?" and typically by an assumption that PA analyses, once again, negate the possibility of agents enjoying autonomy and influence from their principals. The most common cause of this misunderstanding, it seems, arises from scholars who extrapolate too readily from the very early work of Garrett (1992) and Garrett and Weingast (1993), who drew upon PA analysis in a very preliminary way that almost certainly did underestimate the autonomy of the ECJ and other international agents; in later work, however, Garrett and his colleagues retreated from this extreme position, and began to generate analyses that were more discriminating in identifying the possible sources and limits of ECJ discretion (Garrett 1995; Garrett, Schulz and Kelemen 1998). More broadly, while it may be true that individual scholars bring particular biases to the study of supranational institutions like the ECJ (Kassim and Menon 2003), these biases are extrinsic to PA analyses, which when employed properly allow us to problematize, rather than prejudge, the autonomy and influence of international agents.

A third and more understandable red herring has to do with PA assumptions about the preferences of agents. Most PA analyses make simplifying assumptions about the preference of agents, often assuming that they are preference outliers along some relevant dimension of policy (e.g. environmentalists at the EPA, monetarists at central banks, etc., or more generally budget or competence-maximizers). While these assumptions are 
typically and properly explicit, there is a sometimes implicit assumption that agents, in their efforts to maximize their expected utility, will stop short in their actions of irritating their principals and bringing down sanctions - such as legislative overruling or recontracting - upon themselves, and that agents prefer as much discretion from their principals as they can possibly get. Karen Alter refers to such implicit assumptions when she argues that international courts (ICs), as "Trustee-Agents" (see below) "will be guided more by professional norms than by concerns about Principal preferences, sometimes dying on their sword rather than be seen as caving to political pressure" (Alter 2006: 496). Alter's insight here is an important one: Insofar as PA analysts make the implicit assumption that agents seek to avoid sanctioning by their principals at all costs, they may well be mistaken, and the judicial realm in particular is replete with anecdotal examples of judges interpreting constitutional or statutory law in accordance with their legal beliefs, and inviting the legislature to overturn that decision through new legislation if they disagree. Furthermore, as Claus-Dieter Ehlermann has suggested ${ }^{3}$, judges may actually prefer to be legislatively overturned by their principals, rather than the alternatives of either (a) adopting a nakedly political decision to assuage political principals or (b) asserting their discretion in the face of persistently frustrated majorities at the expense of their own legitimacy. In this sense, Ehlermann continues, the difficulty of overturning judicial decisions in consensus-based organizations like the World Trade Organization is not a resource but a problem for international judges, whose legitimacy could potentially be enhanced if member-state principals could more easily overturn decisions with which they disagree. In spite of these insights, I am inclined to refer to this critique as a red herring, insofar as PA analysis can accommodate a range of assumptions about actor preferences, and is therefore in principle consistent with observations put forward by scholars like Alter and Ehlermann about the preferences of international judges.

A fourth and final red herring is the frequent observation that PA analysis does not provide us with a complete theory of, say, international courts or monetary policy, and is therefore not useful. At one level, this critique is entirely correct: PA analysis is a mid-level theory about the dyadic relationship between a principal (or principals) and its

\footnotetext{
${ }^{3}$ In a personal communication (June 2002); see also Ehlermann 2003.
} 
agent (or agents), abstracting almost entirely away from third parties. Furthermore, PA models typically black-box the internal workings of both state principals and IO agents

(e.g. bureaucracies and courts), adopting simplifying assumptions about both actors in order to model the relationship between them. For this reason, it is quite true that PA models cannot claim to offer a complete theory of judicial or monetary politics, and that any such complete theory must in that sense "go beyond" principal-agent analysis.

Nevertheless, I would argue that PA analyses, if incomplete, provide a useful starting point for theorizing about both delegation decisions and subsequent relations between principals and agents - including the possibility that agents like courts and central banks enjoy extensive discretion from their principals, and hence that the primary influences on those agents may come from third-party actors like markets, lower courts, or individual litigants. Furthermore, PA models, as rationalist theories, are compatible with a wide range of other rationalist mid-level theories, and thus can easily serve as one of several building blocks of a more ambitious theory of monetary policy, judicial politics, or whatever (Moravcsik 1998). A more damning critique would be, not simply that principal-agent approaches are limited to modeling a single dyadic relationship, which is quite correct, but that principal-agent approaches model that relationship incorrectly - a point to which I will return below.

\section{Theoretical Disagreements: Two Logics of Delegation?}

While the aforementioned issues are, in my view, red herrings, Giandomenico Majone's work on delegation in the European Union has raised a more complex and vexing issue, namely the author's distinction of two "logics of delegation": one logic informed by the demand for policy-relevant expertise, in which principals delegate executive functions to against within relatively constraining control mechanisms; and a second logic, guided by the logic of credible commitments, in which principles deliberately insulate their agents - or, in Majone's terms, "trustees" - so that those trustees may implement policies to which the principals themselves could not credibly commit. At the extreme, Majone suggests, such a "fiduciary relationship" may lead principals to undertake a "complete, and in some cases irrevocable" transfer of their "political property rights" in a given issue-area to their trustees (Majone 2001: 113). In 
the case of the EU, Majone argues, member state principals have delegated powers in EU treaties primarily to ensure credible commitments, and in these areas the EU's supranational organizations (e.g., the European Court of Justice [ECJ], and the Commission in some of its regulatory and enforcement capacities) approximate trustees, with substantial amounts of discretion. By contrast, he suggests, member states delegate primarily technical and informational functions in EU secondary legislation, and design traditional oversight mechanisms to limit their discretion.

Majone's account is useful in distinguishing between two rationales for delegation - one informational, the other based on credibility of commitments - but in doing so it unnecessarily dichotomizes the two logics of delegation, creating two entirely separate categories of agents/trustees and hypothesizing entirely distinctive motivations for delegation in each case. ${ }^{4}$ In the case of a true trustee - one to whom political principals had ceded a complete and irrevocable transfer of political property rights - we might indeed be able to jettison principal-agent analysis, which would be useful in explaining the act of delegation but not the subsequent behavior of the trustee, who would subsequently be free to act entirely without regard to the principals that had surrendered their political property rights. As an empirical matter, however, Majone's scenario of a complete and irrevocable transfer of political property rights is a theoretical limiting condition (Discretion = 1, in Epstein and O'Halloran's [1999] metric), which is rarely if ever realized in practice, particularly in international politics. Even in the areas of extensive, Treaty-based delegation to EU agents such as the European Central Bank (ECB) and the ECJ, member-state principals typically specify a detailed and constraining mandate and mandatory administrative procedures, and retain for themselves the power of appointment, the power to remove individuals from power for criminal behavior, and the ultimate - if difficult to use - power to recontract with the agent by changing its statute or the Treaty establishing it. If we define trustees as enjoying complete and/or irrevocable transfers of political property rights, then these actors are not trustees; if, on the other hand, we define trustees as simply those actors who are granted great discretion

\footnotetext{
${ }^{4}$ Put differently, Majone conflates in his definition both the causes of delegation (commitments vs. information) and the effects of delegation (high vs. low discretion), making it difficult to disentangle these two variables. Nevertheless, both Franchino (2002) and Pollack (2003: 91-107) have attempted to operationalize Majone's categories, and both found that the discretion of EU supranational institutions varies more continuously, and less dichotomously, than Majone's categorization suggests.
} 
and broad mandates, then actors like the ECB and the ECJ seem to fit within the definition of agents as understood in the existing literature.

In recent years, variants on Majone's agent/trustee dichotomy have been employed in a number of subsequent studies of international delegation. Grant and Keohane (2005: 31), for example, distinguish clearly between what they call "discretionary authorities" and "instrumental agents." 5 In the case of discretionary authorities, they argue, principals "do not expect to direct the power-wielders' behavior beyond defining official duties," and fall back exclusively on ex post mechanisms for sanctioning abuses of power. In the case of instrumental agents, on the other hand, "mechanisms to direct the actions of power wielders ex ante are also employed."

This distinction seems more useful than Majone's, defining the two categories strictly in terms of the structure of delegation and not conflating principals' motives with agents' (or trustees') discretion. Nevertheless, it seems to me that even Grant and Keohane's distinction needlessly dichotomizes what should be a continuous variable, "discretion," since in practice the mandates of "discretionary authorities" are not dichotomous with those of instrumental agents but can vary along a continuum. Consider the US Federal Reserve and the European Central Bank, two widely cited trustees that have been granted fiduciary powers by their respective principals to adopt monetary policies, often in the face of considerable short-term displeasure among their principals. Despite these similarities, neither the Fed nor the ECB enjoy a complete and irrevocable transfer of property rights. Nor do the two banks enjoy the same degree or type of discretion, despite both being "trustees." The Fed, for example, enjoys a relatively broad mandate, while the ECB has a more constraining mandate that clearly prioritizes price stability rather than, say, economic growth; yet the mandate and the powers of the Fed can be altered by a majority vote of Congress, while the ECB Statute can be changed only by a unanimous agreement of the member states, a situation that approximates - but still falls short of - a complete and irrevocable transfer of political property rights. By labeling these organizations dichotomously as "trustees, not agents," we lose sight of the central fact that the discretion of these "trustees" is not absolute but variable, and should

\footnotetext{
${ }^{5}$ See also Alter 2006 and Beach 2004, both of whom apply the agent/trustee distinction to the study of the ECJ and other international courts.
} 
be subject to systematic analysis. Principal-agent analysis is not irrelevant to such cases - on the contrary, PA analysis provides a useful starting point by explaining and establishing the sources and the potential limits of the extraordinary discretion enjoyed by central banks, courts, and other "trustees."

In sum, and putting it plainly, Majone's analysis is theoretically useful in restating the reasons why principals might delegate very extensive discretion to their agents, and in identifying the possibility that, at the limit, state principals might create international trustees to which they effect a complete and irrevocable transfer of political property rights (i.e., sovereignty). In theoretical terms, however, Majone's distinction needlessly dichotomizes a continuous range of principals' motivations for delegation as well as a continuous range of agents' discretion. ${ }^{6}$ In empirical terms, finally, I know of no act of international delegation that can be characterized as a complete and irrevocable transfer of sovereignty, and hence for the universe of cases in which I am interested, principalagent analysis remains a productive and useful language through which to understand and explain delegation and agency at the international level; and the agent/trustee distinction being embraced by an increasing number of scholars emerges, for me, as yet another red herring.

\section{Empirical Disagreements: Does PA Really Capture the Causes of International Delegation and of Agency?}

The final, and most challenging, set of critiques argues that principal-agent models may be internally consistent and theoretically coherent, but that they systematically fail to identify correctly either (a) the reasons and the conditions under which state principals delegate powers to international agents, or (b) the subsequent autonomy and influence of international agents vis-à-vis their principals. These are both empirical and theoretical critiques, which argue that PA accounts get wrong the real reasons why state principals delegate powers to agents or the most important sources of agents' autonomy, and that alternative theoretical accounts - typically sociological

\footnotetext{
${ }^{6}$ It is for this reason that I, in my own work on supranational organizations of the EU (Pollack 2003), have relied on Epstein and O'Halloran's (1999) continuous 0-1 scale of discretion, rather than on Majone's dichotomous distinction between agents and trustees.
} 
institutionalist or constructivist - might do a better job of explaining the empirical reality of delegation and agency in international politics. Let us consider each in turn.

\subsection{Alternative Accounts of Delegation}

With regard to the delegation stage, it is worth noting that PA approaches, while in agreement on the claim that principals delegate powers primarily to reduce the transaction costs of cooperation, identify a fairly wide range of transaction-cost-reducing functions that such agents can perform, including: monitoring compliance with agreements; solving problems of incomplete contracting; providing technical expertise; providing independent and credible economic regulation or monetary policies; locking-in particular political agreements (which the principals' successors might otherwise undo); shifting blame for unpopular decisions; and reducing instability by providing for a single legislative agenda setter (Kassim and Menon 2003: 123-4). These functions are most likely to be delegated, in such models, under specific conditions, including a high demand for credible commitments ${ }^{7}$ or for policy-relevant expertise ${ }^{8}$, which are clear in theory although difficult to measure in practice (Epstein and O'Halloran 1999, Pollack 2002).

Critics of the PA approach to delegation have contested this account in two ways. The first is primarily methodological, on the grounds that it is difficult, if not impossible, to derive reliable measures of abstract variables like "inherent uncertainty," demand for credible commitments, or even of the preferences of principals and agents, and that PA hypotheses about delegation are either tested badly, or are indeed impossible to test. ${ }^{9}$ There is, as I have argued elsewhere, much to this critique, and scholars should indeed

\footnotetext{
${ }^{7}$ Demand for credible commitments can, in turn, be a function of other variables, including (a) a strong temptation to cheat on agreements, as in classic PD models; (b) time-inconsistency problems, where principals worry about the overturning of their preferred policies down the road; and (c) specific policies for which costs are concentrated and benefits are diffuse (Pollack 2003: 29-32)

${ }^{8}$ Demand for policy-relevant expertise, in turn, is typically seen as a function of the complexity or “inherent uncertainty" of an issue-area (Epstein and O'Halloran 1999), although it may also vary as a function of the expertise controlled by the principals themselves. In domestic politics, for example. legislative principals with limited staffs may have a strong need for policy-relevant expertise, and hence delegate powers in complex issue-areas, whereas in international politics member-state principals are likely to have strong domestic sources of expertise, and have weaker informational incentives to delegate such powers to international organizations (Moravcsik 1998; Pollack 2003: 380).

${ }^{9}$ See e.g. Alter (2006: 465), who argues in the case of international courts that, "Adjudicating the competing claims is likely impossible because of the fungibility of state preferences, difficulties measuring slippage, and overdetermination problems."
} 
derive their measures or proxies for such variables with care and treat their empirical findings with some caution (Pollack 2002; 2003: 59-72). The difficulty of measuring abstract theoretical concepts empirically is not, however, limited to PA analyses but affects a wide range of theories (most certainly including constructivist ones) and as such does not specifically infirm the PA approach.

A second critique of PA delegation models is more profound, namely that in the empirical world, political principals - both domestically and internationally - may delegate powers for reasons other than to reduce the transaction costs of cooperation and policy-making. More specifically, sociological institutionalists (SI) have argued that powers are delegated to political agents not (or not primarily) to reduce transaction costs for principals, but rather because such delegation is widely accepted as legitimate or appropriate by the principals or by their constituents. In an article on central bank independence, for instance, Kathleen McNamara (2002) questions the transaction-cost justification for delegating extensive powers to independent central banks, arguing that the economics literature is inconclusive regarding the purported benefits of such delegation. Rather, she suggests, the spread of independent central banks as an organizational form is an example of normative or mimetic "institutional isomorphism," in which particular institutions are adopted and spread not because of their functional benefits but because such institutions come to be seen as legitimate or appropriate in public discourse. Martha Finnemore (1993) has offered a similar explanation for the widespread adoption of science bureaucracies, prompted by new norms arising from UNESCO in the post-war era, suggesting that functional logics do not explain the timing or the universality of this highly specialized organizational form.

This is a compelling alternative explanation for institutional design and for delegation, and one that PA analysts should not dismiss too quickly. Yet there are problems with such sociological institutionalist claims, which also deserve mention. First, in theoretical terms, one can indeed imagine political principals engaging in purely symbolic acts of delegation - that is, delegation decoupled from any actual transactioncost benefits - where the stakes and the costs of such delegation are low, as in the case of 
national science bureaucracies ${ }^{10}$ or when there is radical uncertainty about the issue in question; but such delegation becomes less likely in cases (such as central banks) where the stakes of delegation are high and the costs and benefits are more clearly understood.

Second, such SI claims about delegation as normative institutional isomorphism, while plausible as prima facie explanations of particular acts of delegation, are exceedingly difficult to distinguish in practice from their PA counterparts, since a high degree of normative legitimacy for an institution may simply reflect an accurate assessment by the public of its functional benefits. To distinguish empirically between PA and SI hypotheses about delegation, one would need to find an empirical measure of a given institution's predicted functional benefits, and then demonstrate that those functional benefits are absent in specific empirical cases, so that only normative or mimetic isomorphism would be left as a convincing explanation. Failing such a decisive test, SI accounts of delegation deserve consideration, but there are theoretical reasons for expecting that purely symbolic delegation will decline as the stakes of delegation increase, and there are methodological obstacles to testing such claims that are at least as great as the methodological challenges of testing PA accounts.

\subsection{Alternative Accounts of Agents' Autonomy}

Perhaps most compelling are a final set of critiques that dispute the PA account of agents' autonomy and influence from their principals. These critiques can be further subdivided into two key claims: (a) that principals rely systematically on sources of influence other than their powers as principals in order to influence their agents, and (b) that agents have both idiosyncratic preferences and multiple sources of influence authority that are not captured by PA analysis. Let us review each claim, very briefly, in turn.

First, in an incisive analysis of international courts, Karen Alter (2006) notes that most PA analysts (a) predict that courts will receive substantial discretion from their

\footnotetext{
${ }^{10}$ Or parsley. In a long-forgotten episode of The Flintstones, Fred and Barney decide to open a drivethrough bronto-burger restaurant. When they go to purchase supplies, their supplier explains to them that they need to buy two tons of parsley to put on the side of the burger, "so that people can throw it away." The parsley, in this view, serves no functional purpose, since almost everyone throws it away, but people expect a sprig of parsley next to their burger, and restaurateurs like Fred and Barney comply - although we might expect their willingness to do so to decline as the price of parsley went up. The question in IR terms is whether independent central banks resemble, in this particular sense, a sprig of parsley.
} 
political principals (which is necessary for courts to provide autonomous and neutral adjudication of disputes), and (b) nevertheless assume that political principals will retain some tools of control over courts and judges, including most notably the possibility (for some judges) of reappointment and the prospects (however remote) of legislative overturning and of recontracting. By contrast, Alter argues forcefully that, while states do indeed have means of influencing (or defying) international courts, these means do not generally arise from the nature of the contract between the principals and the agents, nor do they rely on the threat of recontracting, as PA models typically assert. Instead, Alter argues that other modes of state influence - including the use of rhetorical and legitimacy politics as well as legal avenues such as refusing to consent to jurisdiction and settling out of court - are available to states and are more widely used than traditional control mechanisms. "While these arguments are not per se inconsistent with PA theory, they suggest that PA theory itself will not be very useful in studying the dynamics of variation in international judicial decision-making across cases or even across international courts" (Alter 2006: 468).

More radical departures from PA models are made by constructivist scholars such as Michael Barnett and Martha Finnemore (2004) and Ian Johnstone (2003), who offer very different views about the nature of the relationship between IOs and the states that create them. In Barnett and Finnemore's recent book, for example, the authors take issue with PA analyses on a number of points, three of which deserve mention here. First, they argue, international organizations are bureaucracies, which shapes their behavior in systematic ways that cannot be accounted for by a simple set of assumptions about agent preferences (as in most PA models). More concretely, they argue, IOs as bureaucracies order the world and deal with problems in predictable - and sometimes dysfunctional ways, and any attempt to understand the behavior and the "pathologies" of any international organization must model not only the PA relationship but also the bureaucratic culture that helps to shape IO preferences and behavior.

Second, the authors suggest that international organizations enjoy four distinct power resources, or what they call sources of authority: 
- Delegated authority, which arises from an explicit mandate from the memberstates, and is conditional on satisfactory performance of IOs' delegated tasks;

- Expert authority, which arises from IOs' control of specialized, policyrelevant information;

- Rational-legal authority, which arises from the nature of IOs as bureaucracies and rests on their ability to present themselves as neutral and objective creative of impersonal rules; and

- Moral authority, which arises from IOs' claim to represent the values and interests of the community rather than the partial, self-seeking interests of individual states (Barnett and Finnemore 2004: 20-25).

These four sources, the authors argue, place IOs both "in authority" by virtue of the offices they hold and make them "an authority" by virtue of specific characteristics (expertise, objectivity, neutrality); and the authority thus conferred gives IOs both autonomy and the potential to influence other actors.

A third and final claim in Barnett and Finnemore has to do with the nature of IO power, which they argue is both regulative and constitutive. The claim that IOs regulate state behavior through the adoption of informal rules is, of course, a central claim of PA models, but Barnett and Finnemore (2004: 17) go further, suggesting that, "IOs can also constitute the world as they define new categories of problems to be governed and create new norms, interests, actors and shared social tasks." This constitutive role of IOs, they argue, may be the most profound and important, but it is one to which rationalist theorists have devoted no attention. Along similar lines, Ian Johnstone (2003) has argued that the primary influence of the UN Secretary General arises not from his delegated powers, which are meager, but from his privileged position as a member of an international interpretive community and from his ability to persuade others of the correctness of his position through a process of ongoing legal discourse.

Running through such constructivist work we find an interrelated set of claims: (1) empirical claims about the nature of IO influence; (2) theoretical claims about the sources of that influence (e.g., the significance of moral authority and the constitutive or persuasive powers of IOs); and (3) metatheoretical claims about the "ontological 
blindness" of rationalist (including PA) approaches to the most important sources of IO influence. Ultimately, of course, these metatheoretical claims are troubling only to the extent that the empirical claims are also supported: put simply, if moral authority is a marginal resource for IOs or if the evidence for the persuasive or constitutive power of IOs is weak, then the ontological blindness of rationalism toward such phenomena need not trouble us very much. In that sense, constructivist accounts - no less than rationalist ones - bear the methodological burden of convincing us that the constitutive effects of IOs are significant enough to make constructivism the more powerful theory about the autonomy and influence of IOs. As Barnett and Finnemore (2004: 10-14) concede, however, constitutive claims do not lend themselves readily to falsification, and the best empirical work in this tradition offers essentially plausible narratives in which moral authority and persuasion play a role at the margin in providing some leverage to IOs that otherwise enjoy relatively little formal powers.

Nevertheless, studies like Johnstone's and Barnett and Finnemore's do suggest that IO autonomy and influence may - at least at the margins - rest on sources of authority and on causal and constitutive processes to which rationalist accounts are indeed ontologically blind. If we look at Barnett and Finnemore's four source of authority, for example, one could argue that rationalist PA analyses can model the first two sources (delegated authority and expert authority) effectively, and indeed with greater precision than Barnett and Finnemore do; but the last two sources of authority (legal-rational and moral) lie outside principal-agent analysis and are difficult to reconcile with its core assumptions, as is the prospect of a constitutive role for IOs. To the extent that such sources of authority and such constitutive processes are important in the real world - once again, an empirical question - students of principal-agent relations may have to concede that a competing theoretical approach generates greater leverage on the influence of IOs than principal-agent models.

For the moment, I remain unconvinced that moral authority, persuasion, and constitutive processes are empirically significant enough to induce me to call off my ontological bet in favor of rationalist, principal-agent approaches. But the critiques offered in these works are not red herrings and their research programs promise to enrich our understanding of delegation and agency in international relations. 


\section{References}

Alter, Karen J. (2006). "Delegation to International Courts and the Limits of Recontracting Political Power," in Hawkins et al., Delegation and Agency in International Organizations (New York: Cambridge University Press, forthcoming).

Barnett, Michael, and Martha Finnemore (2004). Rules for the World: International Organizations in Global Politics (Ithaca, N.Y.: Cornell University Press).

Beach, Derek (2004). "Are Courts Agents? An Investigation of the Utility of Modelling the Role and Impact of the ECJ Using P-A Analysis," paper prepared for presentation at the ESRC seminar on "Principal-Agent and the Study of the European Union," Birkbeck, University of London, 7 May.

Bendor, Jonathan, A. Glazer, and Thomas Hammond (2001). Theories of Delegation. Annual Review of Political Science, Vol. 4: 235-69.

Ehlermann, Claus-Dieter. 2003. Experiences from the WTO Appellate Body. Texas International Law Journal, Vol 38: 469--88.

Epstein, David, and Sharyn O'Halloran (1999). Delegating Powers: A Transaction Cost Politics Approach to Policy Making Under Separate Powers (Cambridge: Cambridge University Press).

Finnemore, Martha (1993). "International Organizations as Teachers of Norms: The United Nations Educational, Scientific, and Cultural Organization and Science Policy," International Organization, Vol. 47, No. 4 (Autumn), pp. 565-97.

Franchino, Fabio (2002). "Efficiency or Credibility? Testing the Two Logics of Delegation to the European Commission," Journal of European Public Policy Vol. 9(5), 677-694.

Franchino, Fabio (2001). "Delegating Powers in the European Union," paper presented at the Seventh Biennial International Conference of the European Community Studies Association, Madison, Wisconsin, 31 May-2 June.

Garrett, Geoffrey (1992). "International Cooperation and Institutional Choice: The European Community's Internal Market," International Organization, Vol. 46, pp. 533-60.

Garrett, Geoffrey (1995). "The Politics of Legal Integration in the European Union," International Organization, Vol. 49, No. 1: 171--81.

Garrett, Geoffrey, Daniel Kelemen, and Heiner Schulz (1998). "The European Court of Justice, National Governments and Legal Integration in the European Union," International Organization, Vol. 52, No. 1: 149--76. 
Garrett, Geoffrey, and Barry Weingast (1993). "Ideas, Interests, and Institutions: Constructing the EC's Internal Market," in Ideas and Foreign Policy, edited by J. Goldstein and R. Keohane (Ithaca, N.Y.: Cornell University Press).

Grant, Ruth W., and Robert O .Keohane. 2005. Accountability and Abuses of Power in World Politics. American Political Science Review 99 (1): 29-43.

Hawkins, Darren, David Lake, Daniel Nielsen and Michael Tierney, eds. (2006). Delegation and Agency in International Organizations (New York: Cambridge University Press, forthcoming).

Johnstone, Ian (2003). "The Role of the UN Secretary General: The Power of Persuasion Based on Law," Global Governance, Vol. 9 (3).

Kassim, Hussein, and Anand Menon (2003). "The Principal-Agent Approach and the Study of the European Union: Promise Unfulfilled?" Journal of European Public Policy, Vol. 10, No. 1 (February 2003), pp. 121-39.

Lyne, Mona, Daniel Nielsen and Michael J. Tierney (2006). "Getting the Model Right: Single, Multiple and Collective Principals in Development Aid," in Hawkins et al., Delegation and Agency in International Organizations (New York: Cambridge University Press, forthcoming).

Majone, Giandomenico (2001). "Two Logics of Delegation: Agency and Fiduciary Relations in EU Governance," European Union Politics 2 (1): 103--21.

McNamara, Kathleen (2002). "Rational Fictions: Central Bank Independence and the Social Logic of Delegation," West European Politics 25 (1): 47-76.

Pollack, Mark A. (2002). "Learning from the Americanists (Again): Theory and Method in the Study of Delegation," West European Politics, Vol. 25, No. 1 (January 2002), pp. 200-219.

Pollack, Mark A. (2003). The Engines of European Integration: Delegation, Agency and Agenda Setting in the EU (New York: Oxford University Press).

Tallberg, Jonas (2007). "Executive Politics," in Knud Erik Jorgensen, Mark A. Pollack and Ben Rosamond, eds., The Handbook of European Union Politics (London: Sage Publications, forthcoming). 